BJHS: Themes 2:1-10, 2017. C British Society for the History of Science 2017. This is an Open Access article, distributed under the terms of the Creative Commons Attribution licence (http:// creativecommons.org/licenses/by/4.0/), which permits unrestricted re-use, distribution, and reproduction in any medium, provided the original work is properly cited.

doi:10.1017/bjt.2017.11

\title{
Animal agents? Historiography, theory and the history of science in the Anthropocene
}

\author{
AMANDA REES*
}

The term 'agency' smuggles a notion of the universality of a liberal notion of selfhood, with its emphasis on independence and choice, right into the middle of a conversation about slavery against which that supposedly natural (at least for white men) condition was originally defined. ${ }^{1}$

The reviewers' reports for the papers contained in this issue displayed striking unanimity on one theme - the demand for a definition of agency. Again and again, reviewers exhorted the authors to be clearer on what they meant by this, to identify and locate it more visibly within the empirical and theoretical material at hand, to be more specific about the nature of the work that this concept was doing in their analysis. It seems appropriate, therefore, to begin by discussing what it might mean to talk about 'animal agents', before considering their potential contribution to our understanding of the history of science - or indeed, contemplating the consequences that an animalinformed history of science might make to historiography. After all, even when confined to a purely human application, the concept of agency, together with all of its practical, political and philosophical implications, has long been the focus of intense and sustained scholarly debate.

Itself a historically situated and contingent category, agency becomes an important analytic one for scholars at different times and in different, though related, ways. For example, although the relationship between structure and agency has been at the heart of sociological debate since the founding of the discipline, it became an especially salient issue for social theorists as part of the immediate response to and critique of structuralism. ${ }^{2}$ Sociologists of science keenly contested the nature of material agency in the

\footnotetext{
* Department of Sociology, University of York, UK. Email: amanda.rees@york.ac.uk.

I would like to thank the contributors to this issue for giving me the chance to work with such fascinating material and for their tolerance of occasional micro-management on my part. Additionally, I thank them, as well as Andrew Webster, Jim Whitman and Iwan Morus, for valuable comments on this Introduction. I especially want to acknowledge the work of Jon Agar for everything that he has done to facilitate the appearance of this second issue of BJHS Themes, and for giving me the opportunity to edit it. Finally, I thank Trish Hatton, whose editorial assistance made everything easier.

1 Walter Johnson, 'On agency', Journal of Social History (2003) 37, pp. 113-124, 115.

2 For example, Pierre Bourdieu's An Outline of the Theory of Practice, Cambridge: Cambridge University Press, 1977.
} 
1990s, as part of an efflorescence of post-Edinburgh, post-Kuhnian possibilities for reconceptualizing categories of 'nature' and 'culture' through attention to situated practice. ${ }^{3}$ This attention to the potential of non-human agency found resonance within archaeology, anthropology, history of art and political theory: 'things', it seemed, could and did influence, enable and restrain human endeavour. ${ }^{4}$ For social historians, it had become a particularly important historiographical and epistemological concept with the post-war emergence of 'histories from below', which charted the contributions of those groups that - due to class, race, gender or sexuality - had not traditionally been thought of as key contributors to historical development. In particular, in the United States it became a crucial theme within histories of slavery. ${ }^{5}$ There, the recognition of agency in the context of the violent removal of volition represented the empathic acceptance of shared humanity alongside the vehement political rejection of both institutionalized white supremacy and its abiding consequences. But while it is clear that the recognition of historical agency is often synonymous with the recognition of an individual, group or category's historical significance, it is not always clear, even when dealing solely with human beings, what it actually means to be an 'agent'. Is agency to be found simply in shared humanity? Does it consist in self-directed action and the exercise of an independent will? Is it to be found in the action, or in the intent to act - that is, does it pertain to the body or the mind? Does it depend on making rational choices - in order to clearly distinguish acts of intent from instinctive responses? Or would it be clearer to say that agency resides in deliberate action? If so, how are unintended consequences, failures or mistakes to be understood? Can agency be identified in cooperation with authority as well as recognized in resistance?

As the human sciences have 'turned' towards animals over the past quarter-century, so these questions have increasingly been directed at the history, sociology, economics, politics and practices of animals. The endeavour has been startlingly interdisciplinary, involving environmental historians, rural sociologists, historians of art, philosophers, New Social Historians, political ecologists, urban anthropologists, social psychologists, human geographers and cognitive ethologists - among others. ${ }^{6}$ In so far as tentative conclusions have been reached regarding animal agency, they are encapsulated in Walter Johnson's (2003) epigraph above: that agency/agenthood is still tied far too tightly to

3 Andrew Pickering (ed.), Science as Practice and Culture, Chicago: The University of Chicago Press, 1992; Pickering, 'The mangle of practice: agency and emergence in the sociology of science', American Journal of Sociology (1993) 99, pp. 559-598.

4 Alfred Gell, Art and Agency: An Anthropological Theory, Oxford: Clarendon Press, 1998; Chris Gosden, 'What do objects want?', Journal of Archaeological Theory and Method (2005) 12, pp. 193-211; Jane Bennet, Vibrant Ecology: A Political Ecology of Things, Durham, NC: Duke University Press, 2010.

5 Johnson, op. cit. (1).

6 A review of the animal studies literature is well beyond the scope of this Introduction. Harriet Ritvo's 'On the animal turn', Daedalus (Fall 2007) 136(4), pp. 118-122, gives a short outline of the growth of interest in animals. For a historical perspective see Dorothee Brantz (ed.), Beastly Natures: Animals, Humans, and the Study of History, Charlottesville: University of Virginia Press, 2010; Joshua Specht 'Animal history after its triumph: unexpected animals, evolutionary approaches and the animal lens', History Compass (2016) 14, pp. 326-336. Also see the extensive bibliography maintained by Michigan State University's Animal Studies Program at www.animalstudies.msu.edu/bibliography.php. 
the idea of a rational, liberal, individual self, and one that's 'free, white and twenty-one!' to boot. As an alternative, scholars have offered a number of strategies to open out the notion of historical agency - many, for example, often drawing from a perspective of actor-network theory (ANT), have focused discussions on actants, networks, quasiobjects and assemblages. ${ }^{7}$ Some have stressed the need to situate agency in action, rather than to define it in abstract: only by considering a range of elements and their specific contexts can the phenomena be fully apprehended, if not necessarily accounted for. ${ }^{8}$ The role of the environment has been particularly important here, as researchers have stressed the fact that no action takes place in a vacuum, and that physical and social context can shape intent (agency?) as much as provide the setting in which action takes place. ${ }^{9}$ The question of the existence of unintentional agents has also been raised in relation to this point - the impact of Old World domestic livestock on the ecology and landscape of the New World, for example - a landscape that then (as above) provided the context in which subsequent human intentions, whether settler or Amerindian, were formed. ${ }^{10}$ Intentional animal agency - most viscerally, predators who treat humans as just a kind of meat - has also been noted, perhaps also in the context of the zoogenetically inspired resettling of areas where predators had previously been eradicated. ${ }^{11}$ Others have focused on the identification of different kinds of multiple 'agents' - 'unities', in David Gary Shaw's terms - such as militarized dogs and horses. Agency here is formed in a partnership between two or more individuals, both sharing volition and the intent to proceed in a particular direction, if not necessarily aiming at the same target. Such partnerships, however, also raise potential ambivalences between animal intent, training and instinct. ${ }^{12}$

7 Vinciane Despret, 'From secret agents to interagency', History and Theory (2013) 52, pp. 29-44; Chris Pearson, 'Dogs, history and agency', History and Theory (2013) 52, pp. 128-145; David Gary Shaw, 'The torturer's horse: agency and animals in history', History and Theory (2003) 52, pp. 146-167.

8 Sandra Swartz, 'The world the horses made: a South African case study of writing animals into social history', International Review of Social History (2010) 55, pp. 241-263; David Gary Shaw, 'A way with animals', History and Theory (2013) 52, pp. 1-12; Hilary Tovey, 'Theorising nature and society in sociology: the invisibility of animals', Sociological Ruralis (2003) 43, pp. 196-215; Sean Kheraj, 'Demonstration wildlife: negotiating the animal landscape of Vancouver's Stanley Park, 1888-1996', Environment and History (2012) 18, pp. 497-527; Joshua Specht, 'The rise, fall and rebirth of the Texas Longhorn: an evolutionary history', Environmental History (2016) 21, pp. 343-363.

9 Linda Nash, 'The agency of nature or the nature of agency?', Environmental History (2005) 10, pp. 67-69.

10 Virginia Anderson, Creatures of Empire: How Domestic Animals Transformed Early America, Oxford: Oxford University Press, 2002; Elinor Melville, A Plague of Sheep: Environmental Consequences of the Conquest of Mexico, Cambridge: Cambridge University Press, 1994.

11 Brett Walker, 'Animals and the intimacy of history', History and Theory (2013) 52, pp. 45-67; Mahesh Rangarajan, 'Animals with rich histories: the case of the lions of Gir Forest, Gujarat, India', History and Theory (2013) 52, pp. 109-127; Örjan Kardell and Anne Dahlström, 'Wolves in the early 19th century county of Jonköping, Sweden', Environment and History (2013) 19, pp. 339-370; Jan van der Ploeg, Merlijn van Weerd and Gerard A. Persoon, 'A cultural history of crocodiles in the Philippines: towards a new peace pact?' Environment and History (2011) 17, pp. 229-264.

12 Chris Pearson, 'Between instinct and intelligence: harnessing police dog agency in early twentieth-century Paris', Comparative Studies in Society and History (2016) 58, pp. 463-490; Shaw, op. cit. (7); Clifford R. Sanders, Understanding Dogs, Philadelphia: Temple University Press, 1999; Peter Edwards 'Nature bridled: the treatment and training of horses in early modern England', in Brantz, op. cit. (6), pp. 155-175. 
Similar caveats could be and have been applied to human agency, of course, and the extent to which specific human agency depends on the assemblage of a multiplicity of microbial action has also been raised. But there is another other problem with the phrase 'animal agents', and that is the term 'animal'. When English-speakers use this word, for example, they do not usually mean microbes. Often, they don't even mean fish - since, at least in cultures deriving from the Judaeo-Christian tradition, all animals are by no means created equal. ${ }^{13}$ 'Animal' usually means mammal, and in particular the species that have been domesticated, intentionally or otherwise. When discussing agency, then, does one need to specify what kind of animal is meant - indeed, when it comes to species like horses, dogs or chickens, even what breed one means? Would 'agency' mean the same thing in discussing the lives of a broiler chicken and a free-range hen? ${ }^{14}$ Could horses of different kinds - warhorses, as compared to pack mules, say - both be seen to experience the same kind of agency? Or does making this distinction itself reflect the reading of human class conflict onto the animal canvas, privileging the warrior over the peasant? Further, despite the fact that humans are, of course, also animals, the category 'animal' exists not least in order to define what humans are not and there is a long and shameful history of using animal metaphor in order to justify the bestial treatment of other human beings. Clearly, to discuss 'animal agency' is to raise, implicitly or otherwise, a host of philosophical and political problems that rest uncomfortably within the histories of Western societies. On the one hand, the concept provides a possible path around the speciesism that takes human exceptionalism as given, while on the other it retains the potential to magnify or exacerbate power differentials between and within nations by emphasizing animal agency at the expense of less influential human groups.

Certainly one key consequence of the mainstreaming of animal studies has been the realization of the significant roles played by certain animals in contributing to the emergence and evolution of both capitalism and empire - processes which are not just political and economic, but increasingly acknowledged as geological in their impact. Numerous scholars have documented the contribution made by these animals, who at the most basic of levels represent mobile means of converting fuel into energy into power. ${ }^{15}$ Questions here have ranged around the issue whether these animals represent capital or labour - do these subaltern's subalterns represent the means by which profit is

13 Kaori Nagai, Karen Jones, Donna Landry, Monica Mattfeld, Caroline Rooney and Charlotte Sleigh (eds.), Cosmopolitan Animals, London: Palgrave Macmillan, 2015; Lissa Wadewitz, 'Are fish wildlife?', Environmental History (2011) 16, pp. 423-427.

14 Susan Screpfer and Philip Scranton (eds.), Industrialising Organisms: Introducing Evolutionary History, London: Routledge, 2003.

15 Anderson, op. cit. (10); Gabriel Rosenberg, 'A race suicide among the hogs: the biopolitics of pork in the United States', American Quarterly (2016) 68, pp. 49-73; Sam White, 'From globalised pig breeds to capitalist pigs: a study in animal cultures and evolutionary history', Environmental History (2011) 16, pp. 94-120; Karl Apphun, 'Ecologies of beef: eighteenth-century epizootics and the environmental history of early modern Europe', Environmental History (2010) 15, pp. 268-287; Clay McShane and Joel Tarr, The Horse in the City: Living Machines in the 19th Century, Baltimore: Johns Hopkins University Press, 2007; Donna Landry, Noble Brutes: How Eastern Horses Transformed English Culture, Baltimore: Johns Hopkins University Press, 2008; Ann Norton Green, Horses at Work: Harnessing Power in Industrial America, Cambridge, MA: Harvard University Press, 2008. 
accumulated, or are they themselves actively engaged - through the conversion of grass, or waste, or water into milk, wool, or meat - in its creation? ${ }^{16}$ The answer again often seems to depend on the animal and the extent to which it - whether at individual or species level - cooperated with the efforts of particular groups of humans to direct its breeding to their own advantage in the context of a particular ecological and economic environment. A growing number of interdisciplinary studies in evolutionary and coevolutionary history, for example, are now combining archival work with ethnographic and ethological research in order to illuminate the lived historical experiences of both human and animal. ${ }^{17}$ What is particularly interesting about this work is the way in which its focus is directed as much to the future as to the past: studies of how the historical relationship with large predators, for example, was managed are used to inform guidance on present and potential encounters. The key word here is 'relationship' - and whether or not reciprocity is in fact forthcoming is less relevant than its expectation. Whether or not animals have agency here may not matter - the key point is that the belief that they are capable of both intent and reciprocity itself inflects the shape of human experiences and activities. In that sense, if not any other, animals are capable of inspiring action.

But is human belief really all that is at stake? Ever since the beginning of the 'animal turn', scholars have worried that a history of animals can only ever be a history of human perceptions of animals. ${ }^{18}$ Animals - whether mule or microbe - cannot speak, or represent themselves: they must be represented. While they undoubtedly exist in the historical archives, they appear via human interpretation - interpreted twice over, by both the creator and the reader of the record. Some writers have addressed this by seeking non-documentary evidence - traces on the landscape or within the spoken language, evidence from animal architecture (stables, mousetraps, harnesses, veterinary tools, collars) and so on. Others have used the strategies adopted by earlier efforts to widen the application of agency by social historians - they have focused on the role and influence that certain famous animal individuals have had, and from that extrapolated to other animals who occupy structurally similar roles. Another option has been to take the exercise of the historical imagination a step further and try to imagine what the material, visceral, sensual lived experience of a dog or horse might be. ${ }^{19}$ Famously, we don't know what

16 Jason Hribal, 'Animals are part of the working class: a challenge to labour history', Labor History (2003) 44, pp. 435-453.

17 Specht, op. cit. (8); Apphun, op. cit. (15); White, op. cit. (15).

18 Sandra Swartz, 'But where's the bloody horse? Textuality and corporeality in the "animal turn"', Journal of Literary Studies (2007) 23, pp. 271-292; Molly Mullin, 'Mirrors and windows: sociocultural studies of human-animal relationships', Annual Review of Anthropology (1999) 28, pp. 201-224; Susan J. Pearson and Mary Wiesmantel, 'Does "the animal" exist? Towards a theory of social life with animals', in Brantz, op. cit. (6), pp. 17-37.

19 Clifford Sanders and Arnold Arluke, 'If lions could speak: investigating the animal-human relationship and the perspectives of non-human others', Sociological Quarterly (1993) 34, pp. 377-390; Swartz, op. cit. (8); Jon Coleman, Vicious: Wolves and Men in America, New Haven, CT: Yale University Press, 2008; Gary Marvin, 'Wolves in sheep's (and others') clothing', in Brantz, op. cit. (6), pp. 59-78; Aaron Skabelund, 'Animals and imperialism: recent historiographical trends', History Compass (2013) 11, pp. 801-807; Karen Jones, 'Writing the wolf: canine tales and North American environmental-literary tradition', Environment and History (2011) 17, pp. 201-228. 
it is to be a bat, and if a lion could talk we might not understand him - but the fate of lives and nations has depended on the capacity of (non-academic) humans reliably to predict the reactions of horses and dogs. These efforts at horstory (Sandra Swartz's term) are relatively rare - at least, those produced by academics are - and again depend on the kind of interdisciplinary work that is at the heart of the evolutionary histories mentioned above. ${ }^{20}$ Fundamentally, they depend on concepts, strategies and practices derived from the natural sciences - a blending of history with natural history that is also associated with notions of Deep and Big History. ${ }^{21}$

The danger here, of course, lies in assuming that knowledge of the natural sciences is itself independent of social, or cultural, or economic influence - and here, perhaps, is where the history of science can begin to make a substantial and independent contribution, not just to animal history, but to Deep History, to environmental history and to historiography more generally. All of these foci of intensifying intellectual and political interest are making increasing use of natural-science theory and practice - but this is often done in the absence of the awareness that the sciences themselves have a history, and that it is wise to consider present-day configurations in their developmental and cultural context. ${ }^{22}$ This is by no means intended to disparage the efforts that have already been made to increase inter- and intra-disciplinary cooperation, both within and without the histories of science - but historians of science have a particular contribution and a peculiar (often thankless) public responsibility when it comes to the circulation of narratives of scientific knowledge.

This makes it all the stranger that - in contrast to the example of environmental history - historians of science have been less involved in debating the questions surrounding animal agency. A broad interest in the role of animals in the history of science has been evident for some time, but a specific interest in what animals have done for scientists and the contributions they have made to scientific knowledge, as opposed to how scientists have used animals in their research, has been broadly lacking. As Cassidy et al. point out in this issue in relation to the history of medicine, when thinking of animals, scholars have tended to focus only on the 'standard'

20 Swartz, op. cit. (18).

21 Edmund Russell, 'Evolutionary history: prospectus for a new field', Environmental History (2003) 8, pp. 204-228; Russell, 'Coevolutionary history', American Historical Review (2014) 119, pp. 1514-1528; and also see the other contributions to this roundtable issue on History Meets Biology; Daniel Lord Smail, On Deep History and the Brain, New York: Perseus Publishing, 2008; Andrew Shyrock and Daniel Lord Smail (eds.), Deep History: The Architecture of Past and Present, Berkeley: University of California Press, 2011; Fredrik Jonsson, 'A history of the species?', History and Theory (2013) 52, pp. 462-472; David Christian, Maps of Time: An Introduction to Big History, Berkeley: University of California Press, 2004; J.R. McNeil and W.H. McNeil, The Human Web: A Bird's Eye View of World History, New York: Norton, 2003; Fred Spier, 'The ghost of big history is roaming the Earth', History and Theory (2005) 44, pp. 253-264; J.R. McNeil, 'Observations on the nature and culture of environmental history', History and Theory (2003) 42, pp. 5-43; Ellen Stroud, 'Does nature always matter? Following dirt through history', History and Theory (2003) 42, pp. 75-81.

22 Michael D. Gordin's contribution to an American Historical Review roundtable on History Meets Biology is especially timely here - see 'Evidence and the instability of biology', American Historical Review (2014) 119, pp. 1621-1629. See also Kristin Asdal, 'The problematic nature of nature: the postconstructivist challenge to environmental history', History and Theory (2003) 42, pp. 60-74. 
laboratory inhabitants, and to treat them either as objects of the human gaze or as sites of intellectual or material production. Not only could this point be made with equal force in relation to the category of laboratory animals more generally (but see Langlitz's discussion of Tetsuro Matsuzawa's primate work), but it can also characterize histories of animal science, as well as being reflected in the perceptions of those who study animal behaviour. So, for example, Radick's analysis of the intellectual genealogy of William Thorpe makes the point that traditional histories of biology and ethology tend to treat the Modern Synthesis as a conceptual development inimical to any notions of agency: chance, rather than consciousness (at any level) governed evolutionary development. The papers by Rees, Jones and Langlitz all note the broadly held belief that discussions of animal 'intent' or even the existence of an 'inner life' need to be treated cautiously, if not restricted outright to the popular, rather than the processional, literature - even primatologists, Langlitz argues, don't use 'agency' as either an analytic or a descriptive category. In some ways, then, lack of attention to animal agency on the part of historians of science can be understood: where scientists are silent on the subject, then so are we. ${ }^{23}$

But as the papers in this issue show, despite its wide acceptance, the mechanistic approach is only one aspect of the multiplicity of manners, motives and media through which scientists have embrangled themselves with animals. In the first instance, as the papers by Pettit, Nelson, Jones, Radick and Rees all illustrate, scientists from different disciplinary and national traditions have frequently adopted non-reductionist approaches when dealing with animals, approaches that focus on the theoretical and methodological significance of individual differences of personality and history. Jones shows how individual wolves were treated as animals who 'made history', some becoming 'celebrity' or 'ambassador' animals, for both the scientists and the 'wolf paparazzi' who watched them. Nelson's work on Soviet space dogs documents the extent to which an animal's suitability for experimental work was determined by the way in which they (the dogs) chose to interact within the laboratory context, and the particular responses they showed as individual personalities to both equipment and staff. Pettit's study of the inhabitants of Lester Aaronson's New York laboratory clearly situates Aaronson within a psychobiological tradition, where the focus was on the developmental context of the individual. Aaronson's cats interacted with the laboratory staff, were allowed (at certain points) to move freely around the laboratory - and were referred to by name in print. Radick and Langlitz's papers both discuss the existence of alternative evolutionary epistemologies that permit individuals to take an active role in the process, with Radick's Thorpe making the point not only that habitual behaviour can have evolutionary consequences but also that a purposeful mind might exist behind those habitual actions. Rees's analysis of the popular publications of animal fieldworkers documents the way in which the appreciation of individual action based in a sociohistorical context can grow out of particular methodological choices and conceptual

23 Reflecting this, historians of science have been particularly interested in anthropomorphism: Lorraine Daston and Gregg Mitman, Thinking with Animals: New Perspectives on Anthropomorphism, New York: Columbia University Press, 2006; Robert W. Mitchell, Nicholas S. Thompson and H. Lyn Miles (eds.), Anthropomorphism, Anecdotes, and Animals, New York: SUNY Press, 1996. 
orientations. The Modern Synthesis might have been inimical to animal agency - but the New (sociobiological) Synthesis directed scientific attention squarely to the individual, and to the significance of individual life histories/biographies in understanding the evolution of social life and interaction. ${ }^{24}$

The papers by Holloway and Bear, Saha, Daniels and Mather, and Sayer focus their attention even more strongly on the significance of methodologies and practice, making it clear that agency, when it comes to looking beyond the liberal, rational, individual agent, needs to be understood both in action and in interaction. In different ways, each paper addresses the way that agentive action is understood within the circulation of theoretical and technological knowledge, as information and strategies move between ecologist and angler, engineer and farmer, colonial administrator and local elephant wrangler. What their work documents is the extent to which animal actions and reactions shape the economic, political and cultural landscapes and decisions made by different human groups. Animals are not 'meaty machines', to use Saha's phrase, but - in these instances - animated instruments that are both inarticulate and ingenious, continuously reconfigured through their interactions with each other and with the socio-ecotechnic context within which they exist and on which they act.

The introduction of automatic - robotic - milking machines, for example, means that cows must now come forward individually for milking, which makes it possible to record, intimately and instantly, individual cow productivity. From being 'hidden' within the herd hierarchy, the 'lazy cow' suddenly becomes evident. Whether 'laziness' is the result of temperament or a physical mismatch between cow and machine, the consequences for the cow, and its potential to contribute to the next generation, can be final. Technological innovation thus encounters and influences bovine physical and psychological configurations at both the individual and social level - and further, impacts the farmer's own understanding of the farm and its inhabitants. Individuals, technology, history and geography interact here to change the nature, Holloway and Bear argue, of the farm space. Similarly, Sayer shows how the ingenuity of rats has shaped the farm space over time - in this context, as an effort to control and exclude - but with the addition of feline agents to monitor and manage. Her account of the work of Elton's Animal Bureau shows how researchers found themselves in a position of having to counter rat resourcefulness: different methods of control, whether chemical, mechanical, biological or architectural, having to be used in a complex dance that relied on keeping the rat population as naive, ignorant and inexperienced as possible. Daniels and Mather's exposition of the socio-ecology of the wilful salmon deals with the efforts both to protect and to assist a species in need of support at both the physical and the genetic level, while at the individual level they show that anglers encountered salmon as opponents capable of acting, reacting and fighting for their freedom as part of the catch-and-release fishing programme. In both cases, the agentive potential of

24 This is particularly the case in relation to mammal fieldwork. See Amanda Rees, The Infanticide Controversy: Primatology and the Art of Field Science, Chicago: The University of Chicago Press, 2009; Rees, 'Reflections on the field: primatology, popular science and the politics of personhood', Social Studies of Science (2007) 37, pp. 881-907. 
the salmon tended to be recognized only - as with Jones's account of Aldo Leopold's response to the 'fierce green fire' in the eyes of a dying wolf - posthumously. In contrast, Saha's elephants were valued precisely because of their vital corporeal capacity to produce both knowledge and capital. Even more than most large-bodied domestic species, the elephants of colonial Burma were never fully under human control: guidance and practice on how to manage them in the name of both medicine and profit was both tacit and explicit, and emerged through the daily interactions between species and race within the colonial space.

This introduction began by raising the question of what was meant by 'agency'. If that term is to be understood as the capacity to contribute to the future; as the ability through action, interaction or deliberate inaction to change the outcome of events; as possessing the facility - even under conditions not of their own choosing - to make history, then these papers document a range of different ways in which animals, whether chimpanzee, cow or tapeworm, have done so. Whether in laboratory or farm, museum or field site, river or archive, these papers show that animal activity is not just the object of scientific knowledge, but shapes, directs and (sometimes) obstructs the practices and concepts of scientists as they circulate within communities. In developing these accounts, authors have drawn on a vast range of different sources and resources, ranging from memories, maps and micrographs to bones, films, memos and tools - even including photographs taken by tourists or advertisements for air travel. With the exception of bones - and some chimpanzee-made tools - these resources are all, evidently, created by human action - and as such, their creation and collection represent the immediate crystallization of human, not animal, interests. But by discussing the circumstances of that making, the authors have been able to show that these resources were often formed in specific circumstances of interaction, with animals as independent, if not necessarily self-conscious, entities in those exchanges. In this sense, the concern that animals can have no histories that are not human-made is both a truism and a red herring. As with all histories, in order to assess their significance and use, we must first attend to the conditions in which and through which they were produced.

In this context, of course, we need to be aware that this attention to animal agency was itself produced at a specific historical juncture - in the early twenty-first century, in the aftermath of a succession of liberation movements that have progressively democratized public and private space in the West, paving the way for 'histories from below', whether conceptualized in terms of class, race, gender, sex, species or terrain. And we need to remember, pace Johnson, that historically the notion of agency has been far too tightly tied to the notion of liberal selfhood. It is one that emerged within a specific and contingent historic moment, but has, through its location within the 'universalizing' humanism of the Enlightenment, retained its purchase on the intellectual imagination, particularly in relation to groups that benefit disproportionately from the unequal distribution of economic, social and political power. The ostensive problem of 'animal agency' may, in fact, lie less with the agency of animals and more with the pervasive reification of an (apparently) autonomous human agent, free to take individual decisions and make independent choices. The very fact that the human sciences have for over a century found it so difficult to account for the relationships between structure and agency may 
itself point to the possibility that the wrong questions are being asked, perhaps by the wrong people.

Living as we now (probably) do within the Anthropocene, when the impact of human activity can be measured at the geological level, the importance of understanding the limits of human agency and the dangerous plausibility of continuing to treat 'nature/ animal' as qualitatively different from 'culture/human' in public debates has never been more apparent. Valiant and sophisticated efforts by scholars in science studies to destabilize and reframe that dichotomous discourse have, unfortunately, not been entirely successful in gaining traction within these discussions. It may be that a more productive point of entry could be through the investigations of the agency of non-human animals: certainly, as the studies in this issue show, there are many potential points of connection with non-academic appraisals of, and attention to, animal actions. As somebody once said, many people talk to animals - but very few listen. It is at least possible that, were historians of science to take a more active role in the direction of the 'animal turn', that if we were to talk more about the animal actions that underpin much of our research, we could hold the attention of our audiences more effectively. Regardless of the benefits that such participation would make to our own disciplinary position, we also have a significant contribution to make to the debates in relation to the tendency to 'naturalize' scientific knowledge: animals don't speak for themselves, and neither does 'nature'. At the same time, however, attention to animal agency must not be allowed to obscure the identification, and analysis, of the differential distribution of power along the lines of race, class, gender and sexuality within and between human communities. In the past - and in contrast to some other areas of science studies - the history of science has been highly attuned to both the existence and the consequences of such inequalities: we have important roles to play here, particularly in relation to the integration of non-Western experiences and approaches. Given the fundamental role that scientific and technological innovation have played in creating the Anthropocene, if historians of science are to lead the 'animal turn' anywhere in this era, it should be to the empirical investigation and demonstration of the essential, central role that animals (and other animate non-humans) have played in the creation, support and, increasingly, destabilization of socio-economic, political and philosophical privilege - not least because many, if not most of us, currently benefit from it. 